\title{
Effect of surface morphology on wettability conversion
}

\author{
Xia $\mathrm{KONG}^{a}$, Yawei $\mathrm{HU}^{a, *}$, Xiaofang $\mathrm{WANG}^{a}$, Wei PAN ${ }^{b}$ \\ ${ }^{a}$ College of Chemistry and Chemical Engineering, Shaanxi University of Science and Technology, \\ Xi' an, Shaanxi 710021, China \\ ${ }^{b}$ State Key Laboratory of New Ceramics and Fine Processing, Tsinghua University, Beijing 100084, China
}

Received: April 05, 2016; Revised: July 03, 2016; Accepted: July 31, 2016

(C) The Author(s) 2016. This article is published with open access at Springerlink.com

\begin{abstract}
A hierarchical structural surface of $\mathrm{TiO}_{2}$ film with reversibly light-switchable wettability between superhydrophobicity and superhydrophilicity on metal substrate was fabricated through simply dip-coating method from $\mathrm{TiO}_{2}$ precursor solution containing $\mathrm{TiO}_{2}$ nanoparticles with the average diameter $25 \mathrm{~nm}$ (P25), followed by heat-treatment and modification with fluoroalkylsilane (FAS) molecules. The morphology, phase and crystallographic structure, and chemical composite of the as-prepared $\mathrm{TiO}_{2}$ film were characterized by scanning electron microscopy (SEM), X-ray diffraction (XRD), and X-ray photoelectron spectroscopy (XPS). The wettability of $\mathrm{TiO}_{2}$ film was characterized by a drop shape analyzer. The water contact angle of superhydrophobic $\mathrm{TiO}_{2}$ film was up to $165.6^{\circ}$. Under UV irradiation, the water contact angle decreased and the superhydrophobic $\mathrm{TiO}_{2}$ film became superhydrophilic because of hydroxyl groups absorption on the $\mathrm{TiO}_{2}$ surface. Meanwhile, the surface morphology of $\mathrm{TiO}_{2}$ film, which resulted from the $\mathrm{TiO}_{2}$ nanoparticles added in $\mathrm{TiO}_{2}$ precursor solution, had a significant effect on the wettability conversion of $\mathrm{TiO}_{2}$ film and enhanced the switch from hydrophobicity to hydrophilicity. The wettability could be reversibly switched between superhydrophobicity and superhydrophilicity via alternation of UV exposure and dark storage.
\end{abstract}

Keywords: $\mathrm{TiO}_{2}$; morphology; wettability; reverse conversion

\section{Introduction}

Solid surface wettability is one of the most important properties of materials, which strongly depends on both surface chemical composition and geometrical microstructure [1]. One extreme case of wettability properties, namely superhydrophobic surface with a water contact angle greater than $150^{\circ}$, has aroused considerable interest in recent years because of their potential applications in self-cleaning surfaces,

* Corresponding author.

E-mail: huyawei@sina.com microfluidic devices, textile industries, and possibly anti-icing applications [2-4]. It is demonstrated that superhydrophobic surface can be prepared through either fabricating micro-nanostructured surface on low surface free energy materials or chemically modifying the micro-nanostructured surface with low surface free energy materials, or both [5]. Up to now, a large number of superhydrophobic surfaces have been generated through various techniques, and the micronanostructured superhydrophobic films reported have covered various materials, such as polymers, carbon nanotubes, oxides, metals, and so on [6-11]. The oxides, especially the oxide semiconductors, have attracted more attention in recent years. 
Oxide semiconductors play an outstanding role in many aspects of science and engineering owing to their unique optical, semiconducting, catalytic, magnetic, and piezoelectric properties [12-15]. Therefore, they have practical applications as a key component for the fabrication of piezoelectric transducers, transparent conductive oxides, sensors, light-emitting diodes, and optoelectronic devices. In recent years, there has been increasing interest in the wettability of oxide semiconductors as smart materials [16-22]. Among the large family of oxide semiconductors, $\mathrm{TiO}_{2}$, with the direct band gap energy of $3.55-3.75 \mathrm{eV}$, has been widely used in photocatalysts, hydrogen generation, gas sensing, solar cells, and so on [23-25]. However, the wettability of $\mathrm{TiO}_{2}$ has not been fully studied, especially its wettability conversion [17]. Few of publications on wettability conversion of $\mathrm{TiO}_{2}$ films have been reported, in contrast to the huge number of literatures on $\mathrm{TiO}_{2}$ films [26,27]. Herein, we report a method for preparation of a superhydrophobic $\mathrm{TiO}_{2}$ film, which consists of fabricating a micro-nanostructured $\mathrm{TiO}_{2}$ film from $\mathrm{TiO}_{2}$ precursor solution containing $\mathrm{TiO}_{2}$ nanoparticles and modifying the resultant film with fluoroalkylsilane molecules. The effect of surface morphology of $\mathrm{TiO}_{2}$ film on the wettability conversion is investigated.

\section{Experimental details}

\section{1 Preparation of $\mathrm{TiO}_{2}$ film}

In our experiment, all reagents are analytical grade and used without further purification. Specific process of preparation is as follows.

\section{1.1 Preparation of $\mathrm{TiO}_{2}$ precursor}

$\mathrm{TiO}_{2}$ precursor was prepared through sol-gel method [28]. First, $8.2 \mathrm{~mL}$ tetra- $n$-butyl titanate was dissolved in $5.8 \mathrm{~mL}$ ethanol. The other $5.8 \mathrm{~mL}$ ethanol was mixed with $0.4 \mathrm{~mL}$ water and $0.25 \mathrm{~mL} 68 \%$ aqueous solution of nitric acid, and $0.6 \mathrm{~g} \mathrm{TiO}_{2}$ nanoparticles with the average diameter $25 \mathrm{~nm}$ (P25, containing 80\% anatase and $20 \%$ rutile) were added and ultrasonically dispersed. Then the mixture was added dropwise to the former solution under ice-cooled condition with vigorous stirring. $0.5 \mathrm{~g}$ poly(ethylene glycol) (PEG, $M \approx 2000$ ) was added to the solution as soon as the $0{ }^{\circ} \mathrm{C}$ mixing was finished. The container was sealed with stirring to dissolve PEG completely under atmosphere, and then the $\mathrm{TiO}_{2}$ precursor solution was stirred for another $24 \mathrm{~h}$.

\section{1. 2 Process of $\mathrm{TiO}_{2}$ film}

The glass substrate pre-cleaned was immersed in $\mathrm{TiO}_{2}$ precursor solution for $5 \mathrm{~min}$, and withdrawn with the rate of $3 \mathrm{~mm} \cdot \mathrm{s}^{-1}$. After drying naturally in the ambience, such an operation was repeated two times. Then the specimen was sintered at $450{ }^{\circ} \mathrm{C}$ for 60 min with a heating rate $5{ }^{\circ} \mathrm{C} \cdot \mathrm{min}^{-1}$.

\subsubsection{Surface modification}

The prepared specimen was placed into a $1.0 \mathrm{wt} \%$ ethanol solution of $\mathrm{CF}_{3}\left(\mathrm{CF}_{2}\right)_{7} \mathrm{CH}_{2} \mathrm{CH}_{2} \mathrm{Si}\left(\mathrm{OCH}_{3}\right)_{3}$ (FAS), which had been hydrolyzed by the addition of a threefold molar excess of water. The specimen was left in this solution for $1 \mathrm{~h}$, washed with ethanol, and placed in an oven at $140{ }^{\circ} \mathrm{C}$ for $1 \mathrm{~h}$.

\section{2 Measurement and characterization}

$\mathrm{TiO}_{2}$ gel was obtained from the $\mathrm{TiO}_{2}$ precursor heated at $80{ }^{\circ} \mathrm{C}$ for $20 \mathrm{~h}$. The thermal property of the $\mathrm{TiO}_{2}$ gel was characterized by thermogravimetric analysis (TG, STA 409 PC luxx, Netzsch, Germany) operating in atmosphere at a heating rate of $10{ }^{\circ} \mathrm{C} \cdot \mathrm{min}^{-1}$ from room temperature to $700{ }^{\circ} \mathrm{C}$. The phase and the crystallographic structure of the $\mathrm{TiO}_{2}$ film were characterized by an X-ray diffractometer (XRD, D/max-2550, Rigaku Co., Tokyo, Japan) with $\mathrm{Cu} \mathrm{K \alpha}$ radiation $(\lambda=0.154 \mathrm{~nm})$ at a scan rate of $8\left(^{\circ}\right) \cdot \mathrm{min}^{-1}$ ranging from $20^{\circ}$ to $80^{\circ}$. The surface topography and structure of the $\mathrm{TiO}_{2}$ film were characterized by a field-emission scanning electron microscope (FE-SEM, LEO-1530, Carl Ziess Co., Oberkochen, Germany) operating at $15 \mathrm{kV}$. Dynamic light scattering (DLS) size distribution of $\mathrm{TiO}_{2}$ aggregated particles in the $\mathrm{TiO}_{2}$ precursor solution containing P25 particles was measured by laser diffraction particle size analyzer (Zetasizer ZS, Malvern Instruments Ltd., Malvern, UK). The chemical composition of the $\mathrm{TiO}_{2}$ film modified with FAS was analyzed on an X-ray photoelectron spectroscope (XPS) equipped with a standard monochromatic $\mathrm{Al} \mathrm{K \alpha}$ source $(h v=1486.6 \mathrm{eV})$. Water contact angles were measured with a drop shape analyzer (DSA100, Kruss, Germany) at ambient temperature. Water droplets were dropped carefully onto the surface and the average value of five measurements at different positions of the sample was adopted as the contact angle. The wettability conversion tests of $\mathrm{TiO}_{2}$ film were carried out under UV irradiation from a low pressure $\mathrm{Hg}$ tube (Philips TUV $8 \mathrm{~W}$, the strongest emission at $254 \mathrm{~nm}$ ). 


\section{Results and discussion}

Figure 1 shows the TG pattern of the $\mathrm{TiO}_{2}$ gel obtained from the $\mathrm{TiO}_{2}$ precursor without $\mathrm{TiO}_{2} \mathrm{P} 25$ nanoparticles heated at $80{ }^{\circ} \mathrm{C}$ for $20 \mathrm{~h}$. The result shows that the organic matter in $\mathrm{TiO}_{2}$ gel is decomposed before $450{ }^{\circ} \mathrm{C}$ completely, which indicates that an annealing treatment at a temperature equal to or greater than $450{ }^{\circ} \mathrm{C}$ may be required to eliminate the organism residing in the $\mathrm{TiO}_{2}$ gel.

Figure 2 displays the XRD patterns of $\mathrm{TiO}_{2}$ films. All the diffraction peaks in the pattern of $\mathrm{TiO}_{2}$ film fabricated from the $\mathrm{TiO}_{2}$ precursor solution without $\mathrm{P} 25$ nanoparticles can be well indexed as a pure anatase of $\mathrm{TiO}_{2}$, which is in good agreement with the standard data file (JCPDS Card No. 21-1272). The strong and sharp diffraction peaks reveal that the $\mathrm{TiO}_{2}$ is well

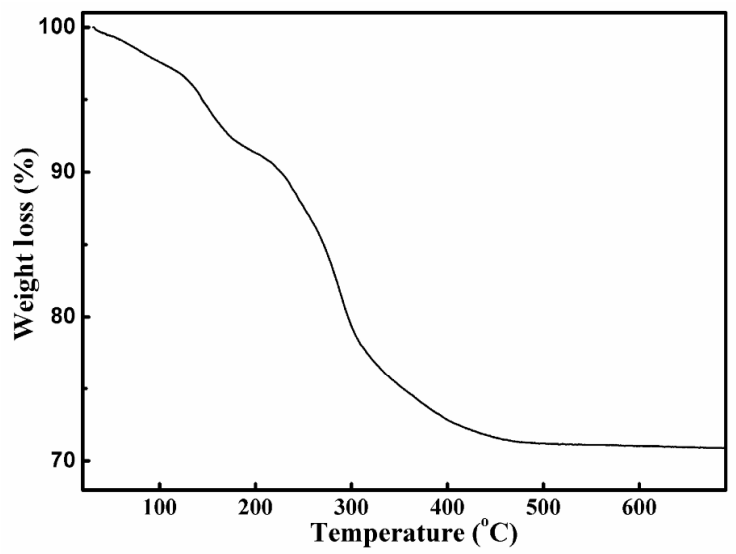

Fig. 1 TG pattern of the $\mathrm{TiO}_{2}$ gel obtained from the $\mathrm{TiO}_{2}$ precursor without $\mathrm{TiO}_{2} \mathrm{P} 25$ nanoparticles.

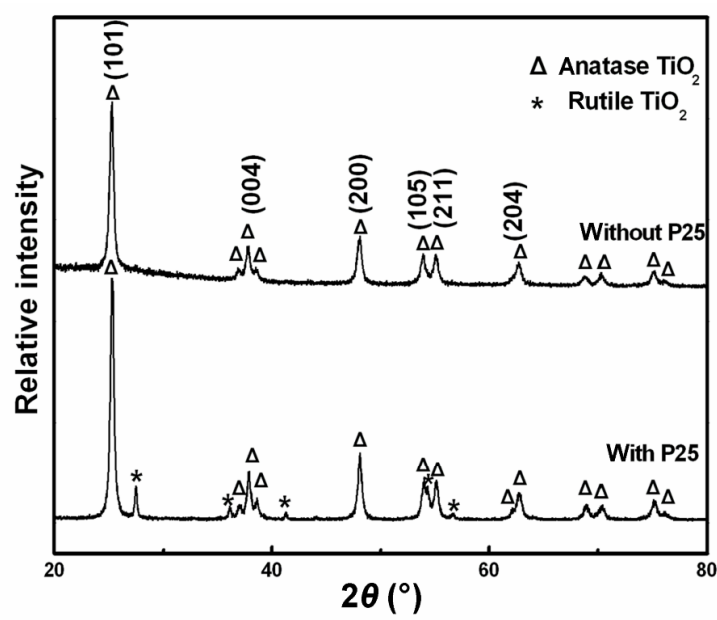

Fig. 2 XRD patterns of $\mathrm{TiO}_{2}$ films fabricated from $\mathrm{TiO}_{2}$ precursor solution with and without $\mathrm{TiO}_{2} \mathrm{P} 25$ nanoparticles. crystallized. However, the XRD pattern of $\mathrm{TiO}_{2}$ film containing $\mathrm{TiO}_{2}$ nanoparticles displays that the film is mainly composed of anatase phase, and comprises little amount of rutile phase which comes from $\mathrm{TiO}_{2} \mathrm{P} 25$ nanoparticles added into $\mathrm{TiO}_{2}$ precursor solution.

The SEM images of the $\mathrm{TiO}_{2}$ films taken with different magnifications are shown in Fig. 3. Figure 3(a) presents a typical SEM image of $\mathrm{TiO}_{2}$ film prepared from the $\mathrm{TiO}_{2}$ precursor solution without $\mathrm{TiO}_{2} \mathrm{P} 25$ nanoparticles, which shows that the film is flat. Its high magnification SEM image (Fig. 3(b)) exhibits that the film is composed of the grains of about $50 \mathrm{~nm}$. However, the surface morphology of $\mathrm{TiO}_{2}$ film fabricated from the $\mathrm{TiO}_{2}$ precursor solution with $\mathrm{TiO}_{2}$ P25 nanoparticles (Figs. 3(c) and 3(d)), which exhibits that the morphology of the $\mathrm{TiO}_{2}$ film is composed of nanoparticles with size about $50-100 \mathrm{~nm}$ and the relatively small nanoparticles are aggregated to form clusters with size about $500 \mathrm{~nm}$, is very different from the one fabricated from the $\mathrm{TiO}_{2}$ precursor without $\mathrm{P} 25$ nanoparticles. As a result, the $\mathrm{TiO}_{2}$ film containing $\mathrm{TiO}_{2} \mathrm{P} 25$ nanoparticles shows hierarchical structure.

The $\mathrm{TiO}_{2}$ films are modified with low surface free energy material FAS, and the wettability is investigated. Before modified with the low surface free energy material FAS, the water droplets could easily spread out on the original $\mathrm{TiO}_{2}$ films without and with $\mathrm{TiO}_{2}$ P25 nanoparticles, which means that the as-prepared original $\mathrm{TiO}_{2}$ films are hydrophilicity. After modified with FAS, the water contact angle of the $\mathrm{TiO}_{2}$ film without $\mathrm{TiO}_{2} \mathrm{P} 25$ nanoparticles is $118.4^{\circ}$ which is inserted in Fig. 3(a). The FAS is one of the widely used self-assembled monolayer molecules to form organic thin film on various oxide substrates to lower the surface free energy. The hydrophobicity of $\mathrm{TiO}_{2}$ film without $\mathrm{TiO}_{2}$ P25 nanoparticles may be mainly owing to the low surface free energy of FAS. While, the $\mathrm{TiO}_{2}$ film with $\mathrm{TiO}_{2}$ P25 nanoparticles displays excellent superhydrophobic property with the water contact angle of $165.6^{\circ}$ after modified with the low surface free energy material FAS (Fig. 3(c)), which could be owing to the complex surface structure containing hierarchical features and the low surface free energy. Higher surface roughness and lower surface free energy play important roles in the superhydrophobicity of the $\mathrm{TiO}_{2}$ film with $\mathrm{TiO}_{2}$ P25 nanoparticles. The more excellent hydrophobicity of $\mathrm{TiO}_{2}$ film with P25 nanoparticles than that without P25 nanoparticles after modified with the low surface free energy material 

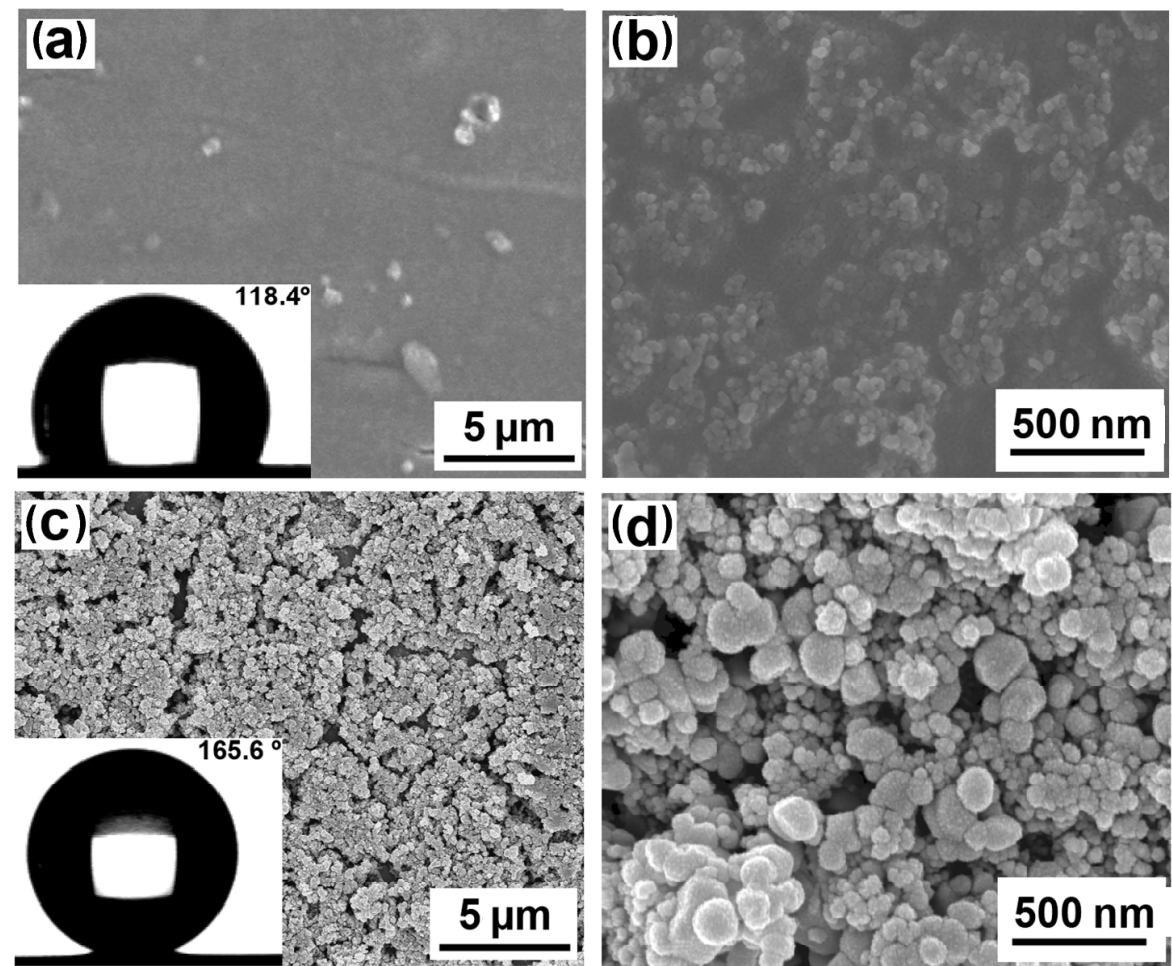

Fig. 3 SEM images of $\mathrm{TiO}_{2}$ films $(\mathrm{a}, \mathrm{b})$ without $\mathrm{TiO}_{2} \mathrm{P} 25$ nanoparticles and (c, d) containing $\mathrm{TiO}_{2} \mathrm{P}_{2} 5$ nanoparticles. Insets are the images of spherical water droplets placed on FAS modified $\mathrm{TiO}_{2}$ films.

FAS indicates that the $\mathrm{TiO}_{2} \mathrm{P} 25$ nanoparticles added into the $\mathrm{TiO}_{2}$ precursor solution have an important influence on formation of superhydrophobicity.

The typical XPS survey spectra of $\mathrm{TiO}_{2}$ films with $\mathrm{TiO}_{2} \mathrm{P} 25$ nanoparticles before and after being modified with FAS are shown in Fig. 4. A strong fluorine peak locates at $687 \mathrm{eV}$ and also the peaks of $\mathrm{C}, \mathrm{O}$, and Ti are observed in this case. This demonstrates that the $\mathrm{TiO}_{2}$ surface is covered by the FAS film which greatly reduces the free energy of the surface.

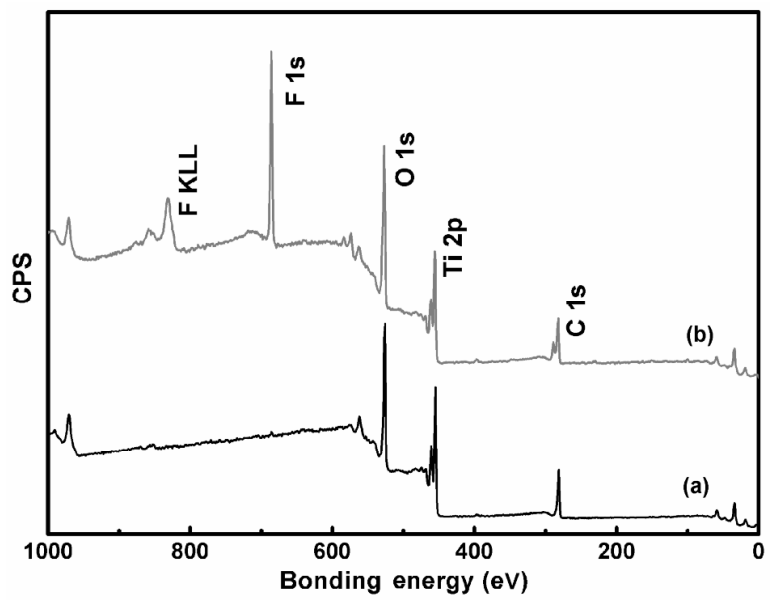

Fig. 4 XPS spectra of the $\mathrm{TiO}_{2}$ films with $\mathrm{TiO}_{2} \mathrm{P} 25$ (a) before and (b) after being modified with FAS.
The particle size of the $\mathrm{TiO}_{2}$ precursor solution containing $\mathrm{TiO}_{2} \mathrm{P} 25$ nanoparticles was measured by the laser diffraction particle size analyzer. The result suggests that the $\mathrm{TiO}_{2} \mathrm{P} 25$ nanoparticles in the $\mathrm{TiO}_{2}$ precursor solution obviously generate aggregation with a size range of 150-1200 nm (most frequent size $1000 \mathrm{~nm}$ ) (Fig. 5), which plays an important role in forming hierarchical structure of $\mathrm{TiO}_{2}$ surface. The hierarchical structure of surface likely leads to the efficient trapping of numerous air pockets in the $\mathrm{TiO}_{2}$ film surface which makes the $\mathrm{TiO}_{2}$ surface minimal contact with the water and contributes greatly to the superhydrophobicity as often discussed in literature [29].

When the $\mathrm{TiO}_{2}$ films are irradiated with UV light for $2 \mathrm{~h}$, they show hydrophilicity (Fig. 6). Changes in water contact angle, as a function of irradiation time, show that the $\mathrm{TiO}_{2}$ film with $\mathrm{TiO}_{2} \mathrm{P} 25$ nanoparticles turns from superhydrophobicity with water contact angle of $165.6^{\circ}$ to hydrophilicity with water contact angle of $30.2^{\circ}$ after $2 \mathrm{~h}$ irradiation, whereas the water contact angle of the $\mathrm{TiO}_{2}$ film without $\mathrm{TiO}_{2} \mathrm{P} 25$ nanoparticles changes from $118.4^{\circ}$ to $52.6^{\circ}$ after $2 \mathrm{~h}$ irradiation. While $\mathrm{TiO}_{2}$ films are irradiated with UV light, photoexcited electrons and positive holes are produced, and certain redox reactions induced by the photoexcited 


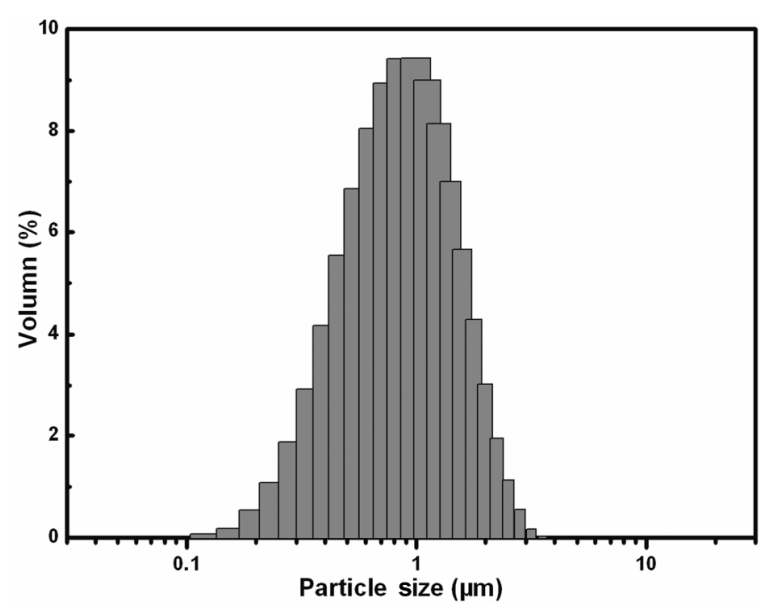

Fig. 5 DLS size distribution of $\mathrm{TiO}_{2}$ aggregated particles in the $\mathrm{TiO}_{2}$ prucursor solution containing $\mathrm{TiO}_{2}$ P25 particles.

electrons and holes may produce extra hydroxyl groups and oxygen vacancies on the surface which could result in the hydrophilicity of $\mathrm{TiO}_{2}$ film $[9,26]$. It is obvious that the hydrophobicity-hydrophilicity conversion rate of $\mathrm{TiO}_{2}$ film with $\mathrm{TiO}_{2} \mathrm{P} 25$ nanoparticles is faster than that of $\mathrm{TiO}_{2}$ film without $\mathrm{TiO}_{2} \mathrm{P} 25$ nanoparticles, and that is mainly governed by the surface morphology of $\mathrm{TiO}_{2}$ film. It is confirmed that rough structure of the surface has a profound influence on wettability.

As described by Wenzel's equation:

$$
\cos \theta_{r}=r \cos \theta
$$

where $\theta_{r}$ is the apparent water contact angle on a rough surface, $\theta$ is the intrinsic water contact angle on a flat surface, and the surface roughness $r$ can enhance both the hydrophilicity and the hydrophobicity of the surface [3]. For the surface mainly composed of FAS

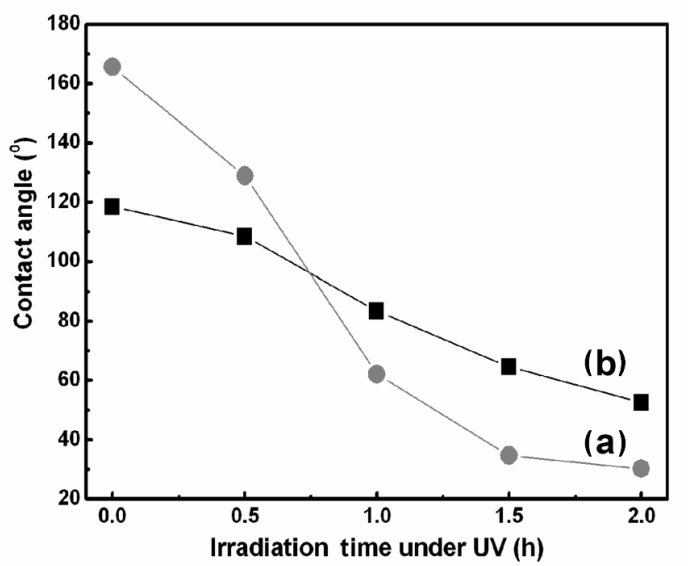

Fig. 6 Water contact angle on $\mathrm{TiO}_{2}$ films (a) with and (b) without $\mathrm{TiO}_{2}$ P25 nanoparticles as a function of the UV illumination time.
( $\theta>90^{\circ}$ for a smooth FAS surface), since $r>1$ for a rough surface in comparison with a smooth area, the water contact angle $\theta_{r}$ of rough surface will increase with the surface roughness $r$, which means that rough surface can enhance the hydrophobicity of surface, and the larger roughness, the more hydrophobicity. Similarly, for the $\mathrm{TiO}_{2}$ film irradiated with UV light, its surface is covered with numerous hydroxyl groups and shows hydrophilicity, and therefore $\theta$ is less than $90^{\circ}$. The water contact angle $\theta_{r}$ of rough surface will increase with the surface roughness $r(r>1)$, that is to say the rough surface can enhance the hydrophilicity, and the larger roughness, the more hydrophibibity. Therefore, for a stimuli-responsive surface, the responsive wettability may be amplified by introducing surface roughness.

When the hydrophilic $\mathrm{TiO}_{2}$ film from UV-irradiated hydrophobic $\mathrm{TiO}_{2}$ film is placed in dark for 10 days, the hydrophilic $\mathrm{TiO}_{2}$ film with $\mathrm{TiO}_{2} \mathrm{P} 25$ recovers to hydrophobicity with water contact angle $156.7^{\circ}$. However, the hydrophilic $\mathrm{TiO}_{2}$ film without $\mathrm{TiO}_{2} \mathrm{P} 25$ recovers its water contact angle just to $86.9^{\circ}$. The conversion has been repeated more than 5 times (Fig. 7). When the $\mathrm{TiO}_{2}$ film is placed in dark, oxygen atoms could replace the oxygen vacancies gradually, and the wettability reconverts from hydrophilicity to hydrophobicity. The conversion rate from hydrophilicity to hydrophobicity of $\mathrm{TiO}_{2}$ film with $\mathrm{TiO}_{2}$ P25 nanoparticles is faster than that of $\mathrm{TiO}_{2}$ film without $\mathrm{TiO}_{2} \mathrm{P} 25$ nanoparticles, which mainly attributes to the surface morphology of $\mathrm{TiO}_{2}$ film.

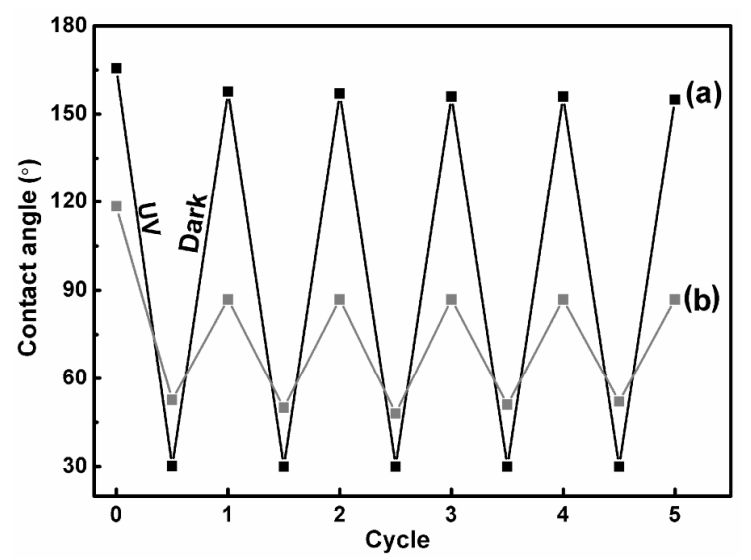

Fig. 7 Water contact angle conversion of $\mathrm{TiO}_{2}$ films (a) with and (b) without $\mathrm{TiO}_{2}$ P25 nanoparticles by alternating UV irradiation and dark storage. 


\section{Conclusions}

In summary, we have fabricated hydrophobic $\mathrm{TiO}_{2}$ film from $\mathrm{TiO}_{2}$ precursor solution containing $\mathrm{TiO}_{2}$ nanoparticles. $\mathrm{TiO}_{2}$ nanoparticles added in $\mathrm{TiO}_{2}$ precursor solution make the $\mathrm{TiO}_{2}$ film show hierarchical structural rough surface. And the rough surface of $\mathrm{TiO}_{2}$ film can distinctly enhance the wettability conversion of $\mathrm{TiO}_{2}$ film between hydrophobicity and hydrophilicity. This research will provide a theoretical and experimental basis for light controlled switch and light controlled dynamic self-cleaning materials.

\section{Acknowledgements}

This work was supported by National Natural Science Foundation of China (No. 21201115), State Key Laboratory of New Ceramics and Fine Processing, Tsinghua University (No. KF201614), and Technology Foundation for Selected Overseas Chinese Scholar of Shaanxi Province of China.

\section{References}

[1] Wang J-M, Wang K, Zheng Y-M, et al. Effects of chemical composition and nano-structrues on the wetting behaviour of lotus leaves. Chemical Journal of Chinese Universities 2010, 31: 1596-1599.

[2] Callies M, Quéré D. On water repellency. Soft Matter 2005, 1: 55-61.

[3] Sun T, Feng L, Gao X, et al. Bioinspired surfaces with special wettability. Acc Chem Res 2005, 38: 644-652.

[4] Nosonovsky M, Bhushan B. Biologically inspired surfaces: Broadening the scope of roughness. Adv Funct Mater 2008, 18: $843-855$.

[5] Tuteja A, Choi W, Ma M, et al. Designing superoleophobic surfaces. Science 2007, 318: 1618-1622.

[6] Zhang X, Shi F, Niu J, et al. Superhydrophobic surfaces: From structural control to functional application. J Mater Chem 2008, 18: 621-633.

[7] Huang X, Zacharia NS. Functional polyelectrolyte multilayer assemblies for surfaces with controlled wetting behaviour. J Appl Polym Sci 2015, 132: 42767.

[8] Liu Y, Wang X, Fei B, et al. Bioinspired, stimuli-responsive, multifunctional superhydrophobic surface with directional wetting, adhesion, and transport of water. Adv Funct Mater 2015, 25: 5047-5056.

[9] Li J, Sun Q, Han S, et al. Reversibly light-switchable wettability between superhydrophobicityand superhydrophilicity of hybrid $\mathrm{ZnO}$ /bamboo surfaces via alternation of UV irradiation and dark storage. Prog Org
Coat 2015, 87: 155-160.

[10] Ju J, Xiao K, Yao X, et al. Bioinspired conical copper wire with gradient wettability for continuous and efficient fog collection. Adv Mater 2013, 25: 5937-5942.

[11] Wang J, Geng G. Simple and eco-friendly fabrication of superhydrophobic textile for oil/water separation. Environ Technol 2016, 37: 1591-1596.

[12] Liu X. Zinc oxide nano- and microfabrication from coordination-polymer templates. Angew Chem Int Edit 2009, 48: 3018-3021.

[13] Song W, Veiga DD, Custódio CA, et al. Bioinspired degradable substrates with extreme wettability properties. Adv Mater 2009, 21: 1830-1834.

[14] Yin J, Cao H. Synthesis and photocatalytic activity of single-crystalline hollow rh- $\operatorname{In}_{2} \mathrm{O}_{3}$ nanocrystals. Inorg Chem 2012, 51: 6529-6536.

[15] Dalrymple OK, Stefanakos E, Trotz MA, et al. A review of the mechanisms and modeling of photocatalytic disinfection. Appl Catal B: Environ 2010, 98: 27-38.

[16] Zhu X, Zhang Z, Men X, et al. Fabrication of an intelligent superhydrophobic surface based on $\mathrm{ZnO}$ nanorod arrays with switchable adhesion property. Appl Surf Sci 2010, 256: 7619-7622.

[17] Xin B, Hao J. Reversibly switchable wettability. Chem Soc Rev 2010, 39: 769-782.

[18] Liu K, Cao M, Fujishima A, et al. Bio-inspired titanium dioxide materials with special wettability and their applications. Chem Rev 2014, 114: 10044-10094.

[19] Yadav K, Mehta BR, lakshmi KV, et al. Tuning the wettability of indium oxide nanowires: Effect of oxygen related defects. J Phys Chem C 2015, 119: 16026-16032.

[20] Hoshian S, Jokinen V, Hjort K, et al. Amplified and localized photoswitching of $\mathrm{TiO}_{2}$ by micro- and nanostructuring. ACS Appl Mater Interfaces 2015, 7: 15593-15599.

[21] Liu Y, Wang X, Fei B, et al. Bioinspired, stimuli-responsive, multifunctional superhydrophobic surface with directional wetting, adhesion, and transport of water. Adv Funct Mater 2015, 25: 5047-5056.

[22] $\mathrm{Hu} \mathrm{Y}-\mathrm{W}, \mathrm{He} \mathrm{H}-\mathrm{R}$, Ma Y-M, et al. Fabrication and wettability conversion of $\mathrm{ZnO} / \mathrm{Ag}$ composite films. Chemical Journal of Chinese Universities 2013, 34: 295-298.

[23] Zhang R, Wu H, Lin D, et al. Photocatalytic and magnetic properties of the $\mathrm{Fe}-\mathrm{TiO}_{2} / \mathrm{SnO}_{2}$ nanofiber via electrospinning. J Am Ceram Soc 2010, 93: 605-608.

[24] Mishra A, Fischer MKR, Bäuerle P. Metal-free organic dyes for dye-sensitized solar cells: From structure: Property relationships to design rules. Angew Chem Int Edit 2009, 48: 2474-2499.

[25] Zhang $\mathrm{R}, \mathrm{Wu} \mathrm{H}$, Lin $\mathrm{D}$, et al. Preparation of necklace-structured $\mathrm{TiO}_{2} / \mathrm{SnO}_{2}$ hybrid nanofibers and their photocatalytic activity. J Am Ceram Soc 2009, 92: 2463-2466.

[26] Eshaghi A, Eshaghi A. Preparation and hydrophilicity of $\mathrm{TiO}_{2}$ sol-gel derived nanocomposite films modified with copper loaded $\mathrm{TiO}_{2}$ nanoparticles. Mater Res Bull 2011, 46: 2342-2345. 
[27] Fan X, Li X, Tian D, et al. Optoelectrowettability conversion on superhydrophobic CdS QDs sensitized $\mathrm{TiO}_{2}$ nanotubes. J Colloid Interface Sci 2012, 366: 1-7.

[28] $\mathrm{Hu} \mathrm{Y,} \mathrm{Huang} \mathrm{S,} \mathrm{Liu} \mathrm{S,} \mathrm{et} \mathrm{al.} \mathrm{A} \mathrm{corrosion-resistance}$ superhydrophobic $\mathrm{TiO}_{2}$ film. Appl Surf Sci 2012, 258: 7460-7464.

[29] Feng L, Li SH, Li Y, et al. Super-hydrophobic surfaces: From natural to artificial. Adv Mater 2002, 14: 1857-1860.
Open Access The articles published in this journal are distributed under the terms of the Creative Commons Attribution 4.0 International License (http://creativecommons. org/licenses/by/4.0/), which permits unrestricted use, distribution, and reproduction in any medium, provided you give appropriate credit to the original author(s) and the source, provide a link to the Creative Commons license, and indicate if changes were made. 